\title{
Clinical and imaging follow-up after exhaustive liver resection of endocrine metastases: a 15-year monocentric experience
}

\author{
S Scigliano ${ }^{1}, R$ Lebtahi $^{1}, F$ Maire $^{2}, J$ L Stievenart ${ }^{1}$, R Kianmanesh ${ }^{3}$, \\ A Sauvanet ${ }^{3}, M P$ Vullierme $^{4}$, A Couvelard $^{5}$, J Belghiti $^{3}, P$ Ruszniewski ${ }^{2}$ \\ and $D$ Le Guludec ${ }^{1}$
}

\author{
Departments of ${ }^{1}$ Nuclear Medicine, ${ }^{2}$ Gastroenterology, ${ }^{3}$ Digestive Surgery, ${ }^{4}$ Radiology and ${ }^{5}$ Pathology, Beaujon University Hospital, \\ 100 Boulevard du Général Leclerc, Clichy 92110, France \\ (Correspondence should be addressed to S Scigliano; Email: sciglsonia@yahoo.fr)
}

\begin{abstract}
Liver metastases are common in gastroenteropancreatic neuroendocrine tumors and significantly impair survival. Hepatic resection is the only potential curative treatment. The records of 41 consecutive patients undergoing exhaustive resection of liver-only endocrine metastases and followed between 1992 and 2006 were reviewed. Patient's outcome and diagnostic accuracy of somatostatin receptor scintigraphy (SRS) and morphological imaging (MI) for detection of recurrences during post-operative follow-up were assessed. All identified primary had been resected. MI studies including abdominal computed tomography (CT) and/or liver magnetic resonance imaging and thoracic CT if indicated were performed every 6 months; SRS timing was decided by referring clinician. Tumor recurrences were confirmed by pathology or subsequent imaging studies. The results of $136 \mathrm{MI}$ and SRS examinations performed within a 30-day interval from each other were retrospectively compared. Median post-operative follow-up was 51 months (7-165). Recurrences developed in 32 patients $(78 \%)$, mainly in the liver $(n=24)$ after a median of 19 months (2-79). Five-year overall and disease-free survival rates were 79 and $3 \%$ respectively. For recurrence detection, sensitivity, specificity, and accuracy were 89,94 , and $91 \%$ for SRS, 68 , 91 , and $74 \%$ for MI respectively. In 11 out of 32 patients (34\%), abdominal or extra-abdominal metastases were detected 15.5 months earlier by SRS than MI. In conclusion, despite exhaustive liver surgery for endocrine metastases, hepatic or extra-hepatic recurrences are frequent and develop early. SRS is highly accurate for the detection of recurrences during post-operative follow-up and permitted early diagnosis in one third of patients; therapeutic implications of this early diagnosis remain to be determined.
\end{abstract}

Endocrine-Related Cancer (2009) 16 977-990

\section{Introduction}

Among patients with gastroenteropancreatic neuroendocrine tumors (GEPNET), 30-80\% present with synchronous or metachronous liver metastases (Moertel 1987, Mignon 2000). The presence and extent of hepatic metastases are the most pejorative prognostic determinants (Moertel 1987, Madeira et al. 1998, Steinmüller et al. 2008). For patients with carcinoid tumors, overall 5-year survival rates are
70-80 and 50\% when liver metastases are absent or present respectively (Janson et al. 1997). Patients with resected gastrinomas have overall 5-year survival rates of $65-100 \%$ when the liver is free of disease, and below 30\% when liver metastases are present (Weber et al. 1995, Yu et al. 1999, Mignon 2000).

Management of patients with liver metastases is heterogeneous and includes loco-regional procedures (liver surgery, orthotopic liver transplantation, 


\begin{tabular}{|c|c|c|c|c|c|c|c|c|c|c|c|c|}
\hline $\begin{array}{l}\text { Patient } \\
\text { no. }\end{array}$ & Gender & $\begin{array}{l}\text { Age }^{\mathbf{a}} \\
\text { (years) }\end{array}$ & Primary tumor & $\begin{array}{c}\text { Liver } \\
\text { metastases/ } \\
\text { completeness } \\
\text { of liver } \\
\text { surgery }\end{array}$ & $\begin{array}{l}\text { Endocrine } \\
\text { activity }\end{array}$ & $\begin{array}{c}\text { Histological } \\
\text { differentiation }\end{array}$ & Ki-67 (\%) & $\begin{array}{l}\text { Mitotic } \\
\text { index }^{\text {b }}\end{array}$ & $\begin{array}{l}\text { Pathological } \\
\text { factors }^{c}\end{array}$ & Adj Ch & $\begin{array}{l}\text { Interval of } \\
\text { recurrence } \\
\text { after } \\
\text { hepatectomy } \\
\text { (months) }\end{array}$ & Outcome \\
\hline 1 & $\mathrm{~F}$ & 45 & Unknown & $\mathrm{s} / \mathrm{R} 1$ & $\mathrm{~N}$ & Moderate & 4 & 1 & NA & - & 8 & $d(49,1)$ \\
\hline 2 & $\mathrm{~F}$ & 29 & Pancreas & $\mathrm{m} / \mathrm{R} 0$ & $\mathrm{~N}$ & Good & 2 & 1 & - & - & 12 & a (3) \\
\hline 3 & $M$ & 37 & Pancreas & $\mathrm{m} / \mathrm{R} 0$ & $\mathrm{~N}$ & Good & 9 & 5 & - & + & l & $a(0)$ \\
\hline 4 & $\mathrm{~F}$ & 32 & Rectum & $\mathrm{m} / \mathrm{R} 0$ & $\mathrm{~N}$ & Poor & 5 & 2 & + & - & 7 & $a(1)$ \\
\hline 5 & $\mathrm{M}$ & 41 & Pancreas & s/R0 & $\mathrm{N}$ & Good & $<2$ & NA & NA & + & 79 & a (2) \\
\hline 6 & $\mathrm{~F}$ & 54 & Pancreas & s/R0 & Glucagonoma & Good & 15 & 5 & + & + & 40 & a (4) \\
\hline 7 & $M$ & 30 & Unknown & s/R0 & $\mathrm{N}$ & Moderate & $2-5$ & NA & NA & + & I & $a(0)$ \\
\hline 8 & $\mathrm{~F}$ & 64 & Unknown & s/Ro & $\mathrm{N}$ & Moderate & 4 & 3 & + & + & 20 & I $(39,1)$ \\
\hline 9 & $\mathrm{M}$ & 52 & Duodenum & s/R0 & Gastrinoma & Good & $2-5$ & 2 & - & - & I & $a(0)$ \\
\hline 10 & $\mathrm{~F}$ & 69 & Small intestine & $\mathrm{s} / \mathrm{RO}$ & $\mathrm{N}$ & Good & $<5$ & 2 & + & - & I & a (0) \\
\hline 11 & $\mathrm{M}$ & 21 & $\begin{array}{l}\text { Celiac } \\
\text { lymph nodes }\end{array}$ & s/R0 & Gastrinoma & Moderate & NA & NA & + & + & 15 & $a(2)$ \\
\hline 12 & $\mathrm{~F}$ & 64 & Small intestine & s/Ro & $\mathrm{N}$ & Good & $<5$ & 5 & - & - & 24 & $a(1)$ \\
\hline 13 & $M$ & 54 & Pancreas & $\mathrm{s} / \mathrm{R} 1$ & $\mathrm{~N}$ & Moderate & 5 & 5 & + & + & 7 & $a(1)$ \\
\hline 14 & $\mathrm{~F}$ & 70 & Small intestine & s/Ro & Carcinoid & Good & 1 & NA & + & - & 27 & $a(1)$ \\
\hline 15 & $\mathrm{~F}$ & 26 & Unknown & s/Ro & Carcinoid & Poor & 3 & NA & NA & - & 13 & $d(118,1)$ \\
\hline 16 & $M$ & 51 & $\begin{array}{l}\text { Celiac } \\
\text { lymph nodes }\end{array}$ & $\mathrm{s} / \mathrm{R} 1$ & $\mathrm{~N}$ & Good & 5 & 2 & + & + & 46 & $a(1)$ \\
\hline 17 & $M$ & 47 & Small intestine & $\mathrm{m} / \mathrm{R} 1$ & Carcinoid & Good & $<5$ & 1 & NA & - & 12 & I $(12,1)$ \\
\hline 18 & M & 68 & Pancreas & $\mathrm{m} / \mathrm{R} 0$ & Gastrinoma & Good & 2 & NA & + & - & 18 & $d(30,1)$ \\
\hline 19 & $\mathrm{~F}$ & 50 & Stomach & s/Ro & $\mathrm{N}$ & Good & $<5$ & NA & NA & + & 17 & a (1) \\
\hline 20 & $\mathrm{~F}$ & 58 & Small intestine & $\mathrm{s} / \mathrm{R} 2$ & Vipoma & Moderate & 5 & NA & + & - & 5 & $d(52,1)$ \\
\hline 21 & $\mathrm{~F}$ & 53 & Pancreas & s/Ro & $\mathrm{N}$ & Moderate & 20 & 7 & - & - & 43 & a (1) \\
\hline 22 & $\mathrm{~F}$ & 51 & Colon & s/R0 & Carcinoid & Good & 5 & 1 & + & - & 22 & $d(47,1)$ \\
\hline 23 & $\mathrm{~F}$ & 75 & Pancreas & $\mathrm{s} / \mathrm{R} 2$ & $\mathrm{~N}$ & Good & 8 & 10 & + & + & 2 & $\mathrm{~d}(16,1)$ \\
\hline 24 & $M$ & 40 & Duodenum & s/R0 & $\mathrm{N}$ & Good & NA & NA & - & - & l & a (0) \\
\hline 25 & $\mathrm{~F}$ & 46 & Pancreas & $\mathrm{m} / \mathrm{R} 0$ & Gastrinoma & Good & 23 & NA & - & + & 45 & $a(1)$ \\
\hline 26 & $M$ & 39 & Pancreas & s/Ro & $\mathrm{N}$ & Poor & 20 & 27 & + & + & 25 & a (2) \\
\hline 27 & $M$ & 21 & Pancreas & $\mathrm{m} / \mathrm{R} 0$ & Gastrinoma & Good & 2 & 1 & + & + & 26 & a (2) \\
\hline 28 & $\mathrm{~F}$ & 63 & Small intestine & $\mathrm{m} / \mathrm{R} 1$ & $\mathrm{~N}$ & Good & $<5$ & 2 & - & - & 8 & I $(52,1)$ \\
\hline 29 & $M$ & 58 & Small intestine & $\mathrm{s} / \mathrm{R} 1$ & $\mathrm{~N}$ & Good & $2-5$ & 10 & + & + & 8 & a (2) \\
\hline 30 & $\mathrm{~F}$ & 48 & Pancreas & s/Ro & Gastrinoma & Good & 2 & 1 & - & - & I & a (0) \\
\hline 31 & $\mathrm{~F}$ & 31 & Small intestine & $\mathrm{m} / \mathrm{R} 2$ & $\mathrm{~N}$ & Good & 1 & 1 & - & - & 58 & $a(1)$ \\
\hline 32 & $\mathrm{~F}$ & 56 & Pancreas & $\mathrm{m} / \mathrm{R} 1$ & $\mathrm{~N}$ & Good & 10 & 2 & + & + & 9 & a (1) \\
\hline 33 & $M$ & 59 & Small intestine & $\mathrm{s} / \mathrm{R} 0$ & Carcinoid & Good & 2 & 1 & + & - & 43 & $a(1)$ \\
\hline 34 & $\mathrm{~F}$ & 28 & Pancreas & s/R0 & Insulinoma & Good & 2 & NA & - & + & I & $a(0)$ \\
\hline
\end{tabular}




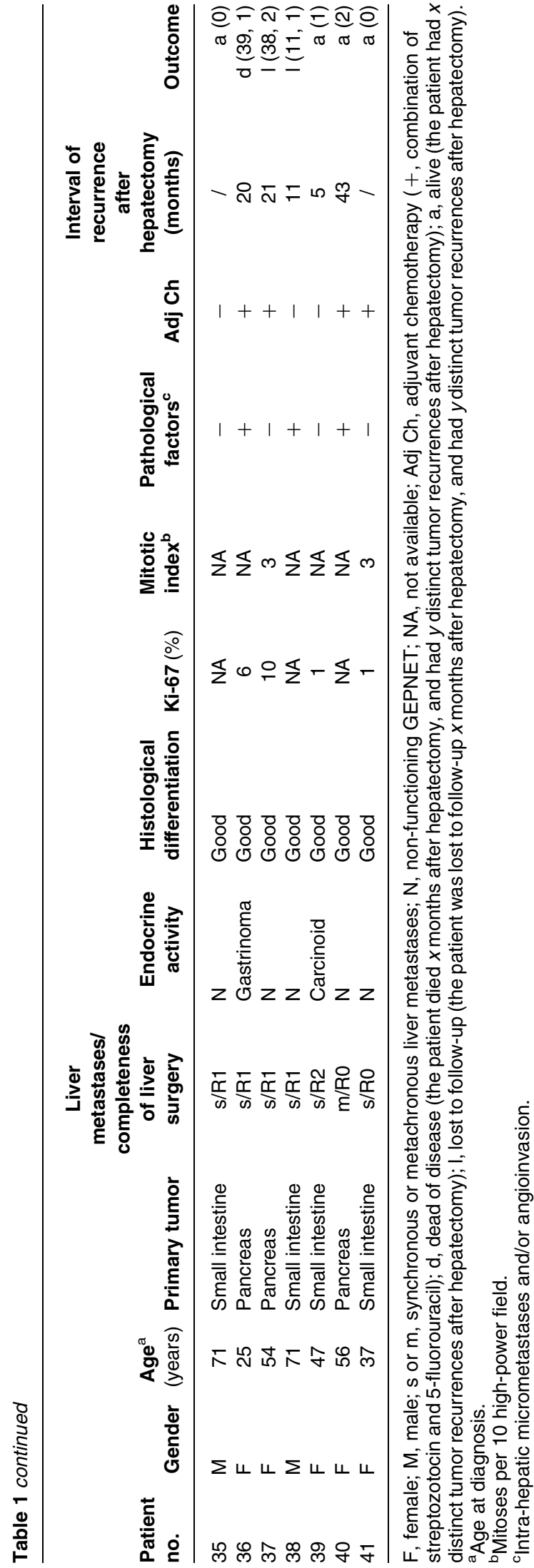

sequential hepatic artery embolization, trans-arterial chemoembolization, and radiofrequency ablation), systemic procedures (chemotherapy and somatostatin receptor radionuclide therapy), and symptomatic medical treatment of the secretory syndrome. But surgery is the only potential curative treatment (Norton 2005, Plöckinger \& Wiedenmann 2005) when complete resection (R0 resection) of all primary tumor and visible liver lesions can be performed, before metastatic spread to local or distant sites occurs. In recent years, aggressive liver surgery for locally advanced and metastatic GEPNET has been proposed, in order to improve duration and quality of life (Que et al. 1995, Chen et al. 1998, Frilling et al. 1998, Ahlman et al. 2000, Chamberlain et al. 2000, Sarmiento et al. 2002, 2003, Elias et al. 2003, Norton et al. 2003).

Imaging studies play an important role in the preand post-operative management of patients with GEPNET. Morphological imaging (MI) techniques such as computed tomography (CT), ultrasonography (US), and magnetic resonance imaging (MRI) are the basic imaging methods for diagnosis and assessment of treatment response. Functional imaging with somatostatin receptor scintigraphy (SRS), which relies on the use of ${ }^{111}$ In-DTPA-octreotide, a radiolabeled somatostatin analog, allows in vivo visualization of the cell-surface somatostatin receptors (mainly subtype 2) expressed by most GEPNET (Reubi et al. 1987, 1990, 2000, John et al. 1996). SRS has been shown to be an effective screening test for initial localization and staging of GEPNET (Plöckinger \& Wiedenmann 2005).

The purpose of this study was to retrospectively analyse the outcome of 41 consecutive patients with GEPNET after exhaustive hepatic surgery for liver metastases as a 15-year experience in a single institution, and to evaluate the respective diagnostic values of MI and SRS studies to identify hepatic and extra-hepatic recurrences during follow-up.

\section{Materials and methods}

\section{Patient population}

The records of 41 consecutive patients with histologically proven GEPNET, followed between 1992 and 2006 at the Gastroenterology Department of Beaujon University Hospital and who underwent liver surgery with curative intent for synchronous $(n=30)$ or metachronous $(n=11)$ metastases, were retrospectively reviewed (Table 1). There were 25 women (61\%) and 16 men $(39 \%)$. Median age at diagnosis was 51 years 
(range: 21-75). Median duration of follow-up from hepatectomy was 51 months (range: 7-165 months). Five patients were lost during follow-up, 11-52 months (median: 38 months) after liver surgery.

All diagnoses were confirmed and characterized according to the World Health Organization criteria (Solcia et al. 2000, Klöppel et al. 2004). Twenty-five patients (61\%) had non-functioning and $16(39 \%)$ had functioning tumors, including gastrinomas $(n=7$ patients), carcinoid tumors $(n=6)$, vipoma $(n=1)$, insulinoma $(n=1)$, and glucagonoma $(n=1)$. Primary tumors were mainly located in the pancreas $(n=17$ patients, $41 \%$ ) and in the small intestine, duodenum excluded $(n=13,29 \%)$. Other sites were the duodenum $(n=2)$, the proximal colon $(n=1)$, the rectum $(n=1)$, abdominal lymph nodes $(n=2)$, and the stomach $(n=1)$. In 4 out of 41 patients (10\%), the primary tumor remained undetected despite thorough pre-operative imaging studies and meticulous intra-operative exploration. No patient had a multiple endocrine neoplasia syndrome. Tumor differentiation was good, moderate, or poor in 76,17 , and $7 \%$ of patients respectively.

Aggressive liver surgery was decided during multidisciplinary meetings for patients fulfilling the following criteria: 1) completely resected (or resectable) primary tumor, except if the primary was unknown; 2) no peritoneal carcinomatosis and no extrahepatic metastases; 3) complete resection of all liver metastases seemed technically possible without compromising liver function; 4) good performance status index and no major comorbidity. Pre-operative imaging work-up included CT of the thorax, abdomen and pelvis, upper and lower digestive endoscopy, as well as SRS to assess the presence or absence of hepatic and extrahepatic metastases. Liver MRI was part of pre-operative investigations in recent years (10 patients). Endoscopic US was obtained for GEPNET located in the duodenum or the pancreas. Intra-operative US was systematically performed to evaluate the liver parenchyma.

All identified primary tumors (as well as regional lymph nodes) were completely removed, either prior to, at the time of, or after liver surgery in 16, 20, and 1 patient(s) respectively. Liver metastases had a median size of $10 \mathrm{~mm}$ (range: $2-170 \mathrm{~mm}$ ). Twenty-eight (68\%) patients had bilateral liver involvement and 19 (46\%) patients had at least ten liver metastases. Liver surgical procedures included tumorectomy $(n=6$ patients, $15 \%)$, segmentectomy $(n=1,2 \%)$, left hepatectomy $(n=7,17 \%)$ associated with concomitant right liver tumorectomy in four patients, right hepatectomy $(n=8,20 \%)$ associated with concomitant left liver tumorectomy in three patients, two-stage hepatectomy $(n=14,34 \%)$ performed as previously reported (Kianmanesh et al. 2005, 2008, Steinmüller et al. 2008), and liver transplantation $(n=5,12 \%)$. For three patients, liver surgery was combined with tumor destruction with alcohol injection for tumors too deep to be resected (one, two, and three tumors respectively). Twenty patients had post-operative (adjuvant) systemic chemotherapy. Patients were considered for adjuvant chemotherapy during multidisciplinary oncologic meetings 1 ) if the primary tumor was pancreatic in patients with non-pancreatic primary tumors, adjuvant chemotherapy was indicated in patients less than 50 years old or patients with at least ten liver lesions or after liver transplantation; 2) provided uneventful post-operative course so that chemotherapy could start within 6 weeks after surgery; 3) if the patients had normal biological data; and 4) if they gave their informed consent. Adjuvant chemotherapy included four cycles of i.v. streptozotocin-5-fluorouracil: 500 and $400 \mathrm{mg} / \mathrm{m}^{2}$ respectively daily for 5 days every 42 days (Maire et al. 2009).

\section{Methods}

After liver surgery, systematic follow-up was based on clinical and symptom evaluation, biology (general and specific endocrine markers), and MI studies (abdominal CT and/or liver MRI, thoracic CT when indicated) every 6 months $( \pm 1$ month). Timing of SRS studies was left to the appreciation of the referring clinician; 27 out of 41 patients underwent systematic SRS studies on a yearly basis. Imaging evaluations could be performed earlier depending on previous clinical, biological, or imaging findings. Consensus about disease status and therapeutic management was reached for each patient during multidisciplinary meetings, on the basis of all available information.

\section{Imaging techniques}

Unenhanced and contrast-enhanced abdominal and pelvic CT and, when indicated, thoracic CT were obtained. Between 1992 and 1996, CT studies were performed with a conventional scanner (Somatom DRG1, Siemens, Erlangen, Germany). Unenhanced and contrast-enhanced scans were performed. Nonionic-iodinated contrast material (300 $\mathrm{mg}$ of iodine per milliliter) was administered i.v. with a power injector. A $60 \mathrm{ml}$ bolus $(2 \mathrm{ml} / \mathrm{s})$ was first injected, followed by a $100 \mathrm{ml}$ infusion $(1 \mathrm{ml} / \mathrm{s})$ during data acquisition. Abdominal imaging included two sets of 5-mm-thick sections, the first set started 35-40 s after the initiation of injection, and the second set immediately after. Liver imaging was completed within 2 min. Oral contrast material was given. Between 1996 and 2001, 
CT examinations were performed with a helical scanner (CT Twin, Elscint, Haïfa, Israël). Helical CT images were obtained before and after a monophasic injection of $140 \mathrm{ml}$ of non-ionic-iodinated contrast material (350 mg of iodine per $\mathrm{ml}$ ) at a rate of $2 \mathrm{ml} / \mathrm{s}$. For abdominal imaging, three sequential breath-hold helical acquisitions were performed: during the hepatic arterial phase (acquisition through the whole liver, collimation: $5 \mathrm{~mm}$; pitch: 1.5 ), the pancreatic phase (acquisition through the whole pancreas, collimation: $2.5 \mathrm{~mm}$; pitch: 1.5), and the portal venous phase (acquisition through the whole liver and pancreas, collimation: $5 \mathrm{~mm}$; pitch: 1.5 ) at 30,45 , and $70 \mathrm{~s}$ respectively, after the initiation of contrast injection. In most cases, oral contrast material was not given, but water was given to obtain complete filling of the duodenal lumen. Since 2001, a Light Speed Ultra spiral scanner (General Electric Medical Systems, Milwaukee, WI, USA) was used. Helical CT images were obtained before and after a monophasic injection of 100-120 ml of non-ionic-iodinated contrast material $(350 \mathrm{mg}$ of iodine per $\mathrm{ml}$ ) at a rate of $3 \mathrm{ml} / \mathrm{s}$. Sequential breath-hold helical acquisitions (collimation: $1.25 \mathrm{~mm}$ ) were performed during the hepatic arterial phase (reconstructed section thickness: $5 \mathrm{~mm}$; pitch: 0.875), the pancreatic phase (reconstructed section thickness: $2.5 \mathrm{~mm}$; pitch: 0.875 ), and the portal venous phase (reconstructed section thickness: $5 \mathrm{~mm}$; pitch: 0.875 ) at 30,45 , and $70 \mathrm{~s}$ respectively, after the initiation of contrast injection. Ingestion of water was obtained.

Liver MRI was done routinely only in recent years, in 16 patients (22 studies). MRI studies were performed with a 1.5-Tesla system (Gyroscan Intera, Philips Medical Systems, Best, The Netherlands) by using a phased-array torso coil for signal reception. Sequences included a breath-hold T1-weighted fast-field echo, a respiratory-triggered T2-weighted fast-spin echo; T1-weighted imaging was repeated during the hepatic arterial (20-25 s delay), portal venous (60-70 s delay), and delayed (5-10 min delay) phases after administration of gadolinium-based contrast medium (Dotarem, Guerbet, France) at a dose of $0.1 \mathrm{mmol} / \mathrm{kg}$ (Vilgrain 2003, Lewin et al. 2006).

SRS studies were performed after i.v. injection of $185 \mathrm{MBq}{ }^{111}$ In-pentetreotide (Octreoscan, Mallinckrodt Medical, Petten, The Netherlands) containing $10 \mu \mathrm{g}$ somatostatin analog. The specific radiochemical purity was checked by chromatography $(>95 \%)$. Scintigraphic planar images covering the wholebody $(4,24$, and $\pm 48 \mathrm{~h}$ after injection) and abdominal single-photon emission-computed tomography
(24 $\mathrm{h}$ after injection) were acquired using a double-head gamma camera with a medium-resolution parallel-hole collimator, as previously reported (Lebtahi et al. 2002).

All MI studies were performed at the Radiology department and all but eight SRS studies at the Nuclear Medicine department at our institution.

\section{Data analysis}

All radiological and scintigraphic images (whether or not performed at our institution) had been individually interpreted at the time of their performance by radiologists or nuclear medicine physicians respectively with strong experience in endocrine tumor imaging. In the retrospective review, we considered all SRS and MI (CT and/or liver MRI) examinations that were performed during post-operative follow-up within a 30-day interval from each other. One hundred and thirty-six imaging explorations met this criterion and were compared. Clinical reports generated at the time of MI or SRS studies were used in the data analysis. All reported lesions were translated into 'recurrence' or 'no recurrence' both for MI and SRS studies: all lesions classified as suspicious of GEPNET recurrence were considered recurrence and lesions reported as probably benign were considered no recurrence, there were no 'indeterminate' interpretations. Histological and/or imaging follow-up findings were used as gold standards: recurrent disease was confirmed in all patients by histological examination and/or by an obvious progression in the number and/or size of the lesions on subsequent imaging studies.

\section{Statistical analysis}

For each patient, survival was calculated from the time of hepatectomy. Survival probabilities were calculated by the Kaplan-Meier method, univariate analysis of survival rates was performed using the log-rank test for categorical variables. A $P$ value of 0.05 was considered indicative of a statistically significant difference. Continuous variables are shown as median and range. Imaging data are presented with $95 \%$ confidence intervals.

\section{Results}

\section{Morbidity-mortality of liver surgery}

There were no perioperative deaths; 7 out of 41 patients $(17 \%)$ had one or more complications with favourable outcome (pulmonary embolism, $n=3$; bile fistula, $n=1$; intra-abdominal abscess, $n=1$; pleural effusion, $n=1$; ascitis, $n=2$; mild and transient hepatic insufficiency, $n=1$; bile leak, $n=1$ ). 


\section{Completeness of surgery}

All identified primary tumors (37 patients) were macroscopically completely removed. Surgical margins were histologically negative (R0 resection) in 34 patients (92\%) and positive (R1 resection) in 3 . Microscopic tumor remnant was observed on the pancreatic section in two patients (one of them was reoperated on to obtain a negative histological margin) and in the third patient on the section margin of a tumor mass corresponding to a primary tumor of the ileum with nodal involvement.

Thirty-seven patients (90\%) had a complete macroscopic resection (R0, $n=26$ patients $(63 \%)$; $\mathrm{R} 1, n=11(27 \%)$ ) of the liver metastases (Table 1); the hepatic security margin ranged from 0 to $20 \mathrm{~mm}$. Four patients $(10 \%)$ had a R2 resection (residual macroscopic tumor; Table 1). In 20 out of 35 patients (57\%; no data available for six patients), histological analysis reported the presence of microscopic tumor foci in the macroscopically normal liver and/or angioinvasion (Table 1).

\section{Outcome of patients after exhaustive liver surgery}

Median duration of post-operative follow-up was 51 months (range: 7-165). Nine patients (22\%) remained disease free, whereas 32 patients $(78 \%)$ developed tumor recurrence after a median of 19 months (range: 2-79; Table 1). Sites of this first recurrence are reported in Table 2: liver ( $n=24$ patients), abdominal $(n=5)$ or thoracic $(n=2)$ lymph nodes, lung $(n=3)$, bone $(n=5)$, thyroid $(n=1)$, and/or s.c. tissue $(n=1)$. Out of 32 patients, 9 experienced at least another hepatic or extra-hepatic tumor recurrence that was accessible to diverse therapeutic options (Table 1).

Table 2 Sites of recurrence (first recurrence) after initial liver surgery

\begin{tabular}{lc}
\hline Sites & $\begin{array}{c}\text { Number of } \\
\text { patients }\end{array}$ \\
\hline Abdominal lymph nodes only & 3 \\
Liver \pm abdominal lymph nodes $^{\text {Liver + site of primary GEPNET }}{ }^{\mathrm{a}}$ & 20 \\
Liver + distant sites $^{\mathrm{b}}$ & 1 \\
Distant sites only & 3 \\
ALL & 5 \\
\hline
\end{tabular}

a Site of the primary GEPNET: pancreas.

bDistant tumor sites: bone (five patients), lung (six patients), s.c. tumors (one patient), thoracic lymph nodes (two patients), and/or thyroid (one patient).
Out of 41 patients, 7 (17\%) died from tumor progression, after a median of 47 months (range: 16-118). No death occurred among the 9 out of 41 disease-free patients.

Overall survival (OS) was $95 \%$ at 3 years and $79 \%$ at 5 years (Fig. 1). Disease-free survival (DFS) was $65 \%$ at 1 year, $25 \%$ at 3 years, and $3 \%$ at 5 years (Fig. 2). Median OS had not been reached, median DFS was 20 months. Univariate analysis of factors potentially predictive of survival included tumor differentiation, endocrine activity, site of the primary (pancreatic or non-pancreatic origin), uni- or bilateral liver involvement, completeness of liver surgery, liver tumor mitotic index and proliferation marker Ki-67, and pathological factors of poor prognosis (intra-hepatic micrometastases and/or angioinvasion; Table 3). Only the presence of poor pathological factors reached statistical significance to predict OS $(P=0.05$, Table 3). Early recurrence detection by imaging studies (prior to median recurrence time) did not influence OS $(P=0.11$; Table 3$)$. Adjuvant chemotherapy had no impact on recurrence: 16 out of $20(80 \%)$ patients who had and 16 out of 21 (76\%) who had no adjuvant chemotherapy experienced recurrences 2-79 months (median: 20.5) and 5-58 months (median: 12.5) after liver surgery respectively.

Repeated interventional procedures were indicated in 16 out of 24 patients who developed liver recurrences: hepatic reresection \pm radiofrequency ablation ( $n=12$ patients, including two patients who received orthotopic liver transplantation); transarterial chemoembolization $(n=3)$; radiofrequency ablation $(n=1)$.

Out of the seven patients who underwent total hepatectomy with liver transplantation, recurrences occurred in four patients (57\%) after a median of 23 months (range: 3-45) and exclusively outside the hepatic graft. The three disease-free-transplanted patients have a follow-up of 35,35 , and 38 months respectively.

\section{Diagnostic values of SRS and MI to detect hepatic or extra-hepatic recurrences}

During follow-up after hepatectomy, the 41 patients were investigated simultaneously by SRS and MI (i.e. when SRS and MI studies were performed within a 30-day interval from each other) in a total of 136 imaging examinations. MI examinations comprised 136 abdominal \pm thoracic $\mathrm{CT}$ and 22 liver MRI performed in 16 patients. SRS and MI studies were concordant in 87 out of $136(64 \%)$ examinations: both methods showed no lesion in 36 out of 87 examinations 


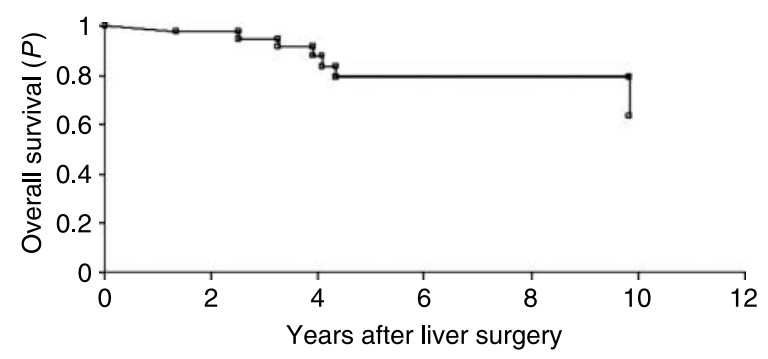

Figure 1 Overall survival rate after exhaustive liver surgery for endocrine metastases.

and depicted the same tumor sites in 51 out of 87 examinations. Lesions were mainly located in the liver (78\%) and abdominal lymph nodes (25\%), less frequently in thoracic lymph nodes, bone, lung, and pancreas. There were 49 out of $136(36 \%)$ discordant examinations, for lesions located in the liver (33\%), abdominal (26\%) or thoracic (16\%) lymph nodes, bone (22\%), and less frequently in lung, pancreas, and thyroid. The diagnosis values obtained on a patientbased analysis are presented in Table 4; results differentiated for the various sites of tumor recurrence and for each imaging technique are reported in Table 5. SRS had higher accuracy, sensitivity, and negative predictive value (NPV) than MI to detect tumor recurrence sites; their specificity and positive predictive value were similar.

When considering all sites of tumor recurrence, in 11 out of 32 patients (34\%) who recurred (25 examinations), SRS showed recurrences earlier than MI. Closer MI studies were then obtained and showed, in all patients, corresponding lesions with a median delay of 15.5 months (range 5-31 months). All cases of recurrence were confirmed by histological analysis and/or by progressive lesions on subsequent MI studies at sites previously abnormal on SRS. Recurrences were located in the liver ( $n=5$ patients; Fig. 3 ), abdominal or pelvic lymph nodes $(n=5)$, thoracic lymph nodes $(n=3$; Fig. 4), bone $(n=2)$, and/or pancreas ( $n=1$; Fig. 5$)$.

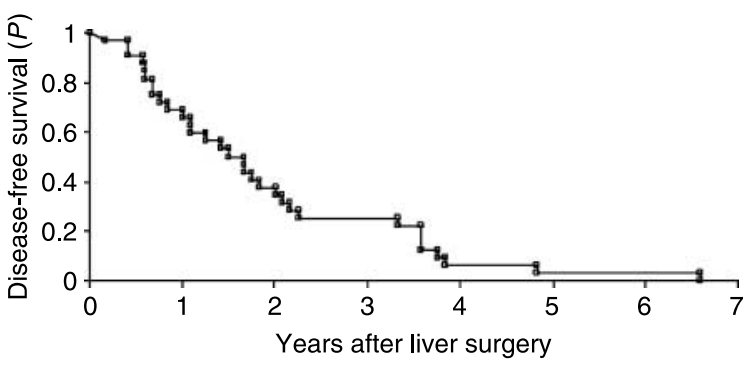

Figure 2 Disease-free survival rate after exhaustive liver surgery for endocrine metastases.
When MI studies subsequently showed the lesions earlier detected by SRS, the size of corresponding lesions ranged from 7 to $22 \mathrm{~mm}$ for liver metastases, from $<10$ to $15 \mathrm{~mm}$ for abdominal or pelvic lymph nodes, and from 6 to $20 \mathrm{~mm}$ for thoracic lymph nodes. The median delay of detection of morphological abnormalities was 12, 12, 23, and 21 months for liver metastases, abdominal or pelvic lymph nodes, thoracic lymph nodes, and bone lesions respectively; the delay was 7 months for the pancreatic lesion. Conversely, MI identified tumor recurrences earlier than SRS in 2 out of 32 patients (6\%): thoracic and abdominal CT showed lung involvement 3 months before lung abnormalities on SRS in one patient and abdominal enlarged lymph nodes 12 months before nodal foci of uptake on SRS in the second patient.

In 11 other patients (34\%; 20 examinations), SRS revealed distant metastases that would otherwise have been ignored if only MI studies were performed: one pelvic recurrent mass ( $n=1$ patient), involvement of thyroid $(n=3)$, bone $(n=6)$, lung $(n=1)$, and/or thoracic lymph nodes $(n=3)$.

\section{Discussion}

Multiple independent studies have advocated aggressive surgical management of hepatic endocrine metastases. Such an approach was found to improve the quality of life in symptomatic patients (Que et al. 1995, Chen et al. 1998, Ahlman et al. 2000, Chamberlain et al. 2000, Sarmiento et al. 2003), and was suggested to prolong survival: 5-year OS rates ranged from 71 to $85 \%$ for hepatectomized patients (Norton 2005) and from 20 to $30 \%$ for historical controls when liver metastases were neither resected nor ablated (Moertel 1987, Chen et al. 1998, Chamberlain et al. 2000) respectively. Surgical resection appears as the treatment of choice when all macroscopic primary tumor and liver metastases can be resected (Norton 2005, Steinmüller et al. 2008). In our series of 41 patients with liver-only metastases, hepatectomy was performed with curative intent and led to 3- and 5-year OS rates of 95 and $79 \%$ respectively with no operative death and low morbidity. These results are consistent with previous reports indicating that aggressive surgery for endocrine hepatic metastases is safely feasible by experienced surgeons in selected patients (Norton et al. 2003, Sarmiento et al. 2003, Kianmanesh et al. 2008). Whether such aggressive approach prolongs survival is, however, difficult to prove unequivocally. Because of the relatively low incidence of endocrine tumors, their markedly heterogeneous biological and 
Table 3 Univariate analysis of prognostic factors after resection of liver endocrine metastases

\begin{tabular}{|c|c|c|c|c|c|}
\hline Factor & $n$ & $\begin{array}{c}\text { Overall } \\
\text { survival (\%) }\end{array}$ & $\boldsymbol{P}^{*}$ & $\begin{array}{l}\text { Disease-free } \\
\text { survival }(\%)\end{array}$ & $\boldsymbol{P}^{*}$ \\
\hline \multicolumn{6}{|l|}{ Tumor differentiation } \\
\hline Good & 31 & 87 & & 26 & \\
\hline Moderate & 7 & 71 & 0.67 & 14 & 0.25 \\
\hline Poor & 3 & 66 & & 0 & \\
\hline \multicolumn{6}{|l|}{ Endocrine activity } \\
\hline Functioning tumor & 16 & 92 & 0.20 & 24 & 0.74 \\
\hline Non functioning tumor & 25 & 69 & & 19 & \\
\hline \multicolumn{6}{|l|}{ Pancreatic origin } \\
\hline No & 24 & 83 & 0.97 & 25 & 0.28 \\
\hline Yes & 17 & 82 & & 18 & \\
\hline \multicolumn{6}{|l|}{ Unit or bilateral liver involvement } \\
\hline Unilateral & 13 & 77 & 0.81 & 23 & 0.90 \\
\hline Bilateral & 28 & 86 & & 21 & \\
\hline \multicolumn{6}{|l|}{ Completeness of liver surgery } \\
\hline Ro & 26 & 88 & & 31 & \\
\hline $\mathrm{R} 1$ & 11 & 82 & 0.12 & 9 & 0.13 \\
\hline $\mathrm{R} 2$ & 4 & 50 & & 0 & \\
\hline \multicolumn{6}{|c|}{ Mitotic index ${ }^{a}$ (data available for 25 patients) } \\
\hline$\leq 2$ & 14 & 85 & 0.64 & 31 & 0.51 \\
\hline$>2$ & 11 & 88 & & 13 & \\
\hline \multicolumn{6}{|c|}{ Proliferation marker (data available for 36 patients) } \\
\hline $\mathrm{Ki} 67 \leq 5 \%$ & 27 & 82 & 0.72 & 22 & 0.82 \\
\hline Ki67> $>5 \%$ & 9 & 78 & & 11 & \\
\hline \multicolumn{6}{|c|}{ Poor pathological factors ${ }^{\mathrm{b}}$ (data available for 35 patients) } \\
\hline No & 15 & 100 & 0.05 & 47 & 0.40 \\
\hline Yes & 20 & 75 & & 10 & \\
\hline \multicolumn{6}{|l|}{ Recurrence diagnosis } \\
\hline$<19$ months after liver surgery & 16 & 69 & 0.11 & & \\
\hline$>19$ months after liver surgery & 16 & 88 & & & \\
\hline
\end{tabular}

${ }^{*} P$ calculated using the log-rank test.

${ }^{\text {a }}$ Mitoses per 10 high-power field.

${ }^{\mathrm{b}}$ Intra-hepatic micrometastases and/or angioinvasion.

clinical presentation, no randomized prospective trial has compared complete resection of liver metastases with no or other therapeutic options in rigorously comparable patients. Moreover, among studies, variable criteria are taken to select patients for liver surgery (liver tumor burden and the absence or presence of minimal extra-hepatic disease) making strict comparison of published survival rates difficult. However, in retrospective studies, a clear benefit of liver surgery was found by Chen et al. (1998) in 15 hepatectomized patients versus 23 non-resected patients (5-year OS of $73 \%$ and 29 respectively), and by Musunuru et al. (2006) in 13 hepatectomized patients versus 35 patients treated medically or by embolization (3-year OS of 83 and $31 \%$ respectively). In both studies, patient groups had similar tumor characteristics and percentage of liver involvement. At our institution, the general approach is to propose liver resection as the first-line treatment in patients with liver-only metastases in whom all primary had been completely removed or is potentially completely removable. Thus, we could not validly compare survivals of our hepatectomized with our nonhepatectomized patients who clearly had more extensive liver and/or extra-liver disease. However, the 5-year OS rate of $79 \%$ observed in our series compares favorably with the 5-year OS rate of $50 \%$ reported in 35 patients with tumor characteristics

Table 4 Patient-based analysis

\begin{tabular}{|c|c|c|c|c|}
\hline & SRS & $95 \% \mathrm{Cl}$ & MI & $95 \% \mathrm{Cl}$ \\
\hline \multicolumn{5}{|c|}{136 examinations } \\
\hline SN & 0.89 & $0.83-0.96$ & 0.68 & $0.59-0.77$ \\
\hline SP & 0.94 & $0.85-1.03$ & 0.91 & $0.81-1.01$ \\
\hline PPV & 0.98 & $0.94-1.02$ & 0.95 & $0.90-1.00$ \\
\hline NPV & 0.75 & $0.62-0.88$ & 0.50 & $0.37-0.63$ \\
\hline Accuracy & 0.91 & $0.85-0.95$ & 0.74 & $0.66-0.82$ \\
\hline
\end{tabular}

95\% Cl, 95\% confidence interval; SN, sensitivity; SP, specificity; PPV, positive predictive value; NPV, negative predictive value. 
Table 5 Results differentiated for the various tumor sites and for each imaging techniques

\begin{tabular}{|c|c|c|c|}
\hline Tumor sites ( $n / 136$ examinations) & Results & SRS & MI \\
\hline \multirow[t]{5}{*}{ Liver (76) } & TP & 70 & 67 \\
\hline & $\mathrm{FP}$ & 0 & 1 \\
\hline & FN & 6 & 9 \\
\hline & SN & 0.92 (70 out of 76 ) & 0.88 (67 out of 76$)$ \\
\hline & $95 \% \mathrm{Cl}$ & $0.86-0.98$ & $0.81-0.95$ \\
\hline \multirow{5}{*}{$\begin{array}{l}\text { Abdominal and pelvic } \\
\text { lymph nodes }(30)\end{array}$} & $\mathrm{TP}$ & 27 & 20 \\
\hline & $\mathrm{FP}$ & 0 & 2 \\
\hline & FN & 3 & 10 \\
\hline & SN & 0.90 (27 out of 30$)$ & 0.67 (20 out of 30$)$ \\
\hline & $95 \% \mathrm{Cl}$ & $0.79-1.01$ & $0.50-0.84$ \\
\hline \multirow[t]{5}{*}{ Thoracic lymph nodes (12) } & $\mathrm{TP}$ & 11 & 5 \\
\hline & FP & 0 & 0 \\
\hline & FN & 1 & 7 \\
\hline & SN & 0.92 (11 out of 12$)$ & 0.42 (5 out of 12$)$ \\
\hline & $95 \% \mathrm{Cl}$ & $0.77-1.07$ & $0.14-0.70$ \\
\hline \multirow[t]{5}{*}{ Lung (8) } & TP & 7 & 8 \\
\hline & $\mathrm{FP}$ & 0 & 0 \\
\hline & FN & 1 & 0 \\
\hline & SN & 0.88 (7 out of 8$)$ & 1.0 (8 out of 8 ) \\
\hline & $95 \% \mathrm{Cl}$ & $0.65-1.11$ & $1.00-1.00$ \\
\hline \multirow[t]{5}{*}{ Bone (16) } & $\mathrm{TP}$ & 16 & 4 \\
\hline & FP & 0 & 1 \\
\hline & FN & 0 & 12 \\
\hline & SN & 1.0 (16 out of 16$)$ & 0.25 (4 out of 16$)$ \\
\hline & $95 \% \mathrm{Cl}$ & $1.00-1.00$ & $0.04-0.46$ \\
\hline \multirow{5}{*}{$\begin{array}{l}\text { Others (thyroid, pancreas, } \\
\text { spleen, cerebral parenchyma, } \\
\text { and breast) (8) }\end{array}$} & $\mathrm{TP}$ & 7 & 2 \\
\hline & FP & 2 & 4 \\
\hline & FN & 1 & 6 \\
\hline & SN & 0.88 (7 out of 8 ) & 0.25 (2 out of 8 ) \\
\hline & $95 \% \mathrm{Cl}$ & $0.65-1.11$ & $-0.05-0.55$ \\
\hline \multirow{5}{*}{$\begin{array}{l}\text { Tumor sites }(n / 136 \\
\text { examinations) all (150) }\end{array}$} & TP & 138 & 106 \\
\hline & FP & 2 & 9 \\
\hline & $\mathrm{FN}$ & 12 & 44 \\
\hline & SN & $0.92(138$ out of 150$)$ & 0.71 (106 out of 150$)$ \\
\hline & $95 \% \mathrm{Cl}$ & $0.88-0.96$ & $0.64-0.78$ \\
\hline
\end{tabular}

TP, true positive; TN, true negative; FP, false positive; SN, sensitivity; $95 \% \mathrm{Cl}$, 95\% confidence interval; ( $n / 136)$, number of imaging examinations depicting involvement of each site for the 41 patients.

close to ours and who were also highly selected (no peritoneal carcinomatosis and no extra-hepatic disease) before hepatectomy (Elias et al. 2003).

We report a very high recurrence rate: 3- and 5-year DFS were 25 and $3 \%$ respectively with a median time to recurrence of 19 months. As already observed, a minority of patients are cured after exhaustive hepatic surgery (Sarmiento et al. 2002, 2003, Elias et al. 2003). Completeness of liver surgery is a major factor influencing development of recurrences (Nave et al. 2001, Sarmiento et al. 2003). Although, liver resection intended to be complete, $37 \%$ of our patients had micro or macroscopically incomplete liver surgery (R1 or R2 resection). Such discrepancy between exhaustive intent of liver surgery and effective results was previously noted by Elias et al. (2003): only 53\% of 47 highly selected patients had a R0 resection. Poor pathological factors (intra-hepatic micrometastases and/or angioinvasion) were present in 57\% of our patients and were the only prognostic parameter found to have a significant impact on OS. All these data indicate that residual microscopic hepatic and/or extra-hepatic disease persists despite thorough pre- and intraoperative imaging explorations and exhaustive liver surgery. In this series, adjuvant chemotherapy did not influence the development of recurrence, as also recently reported in a dedicated study performed at our institution (Maire et al. 2009). This emphasizes 
A

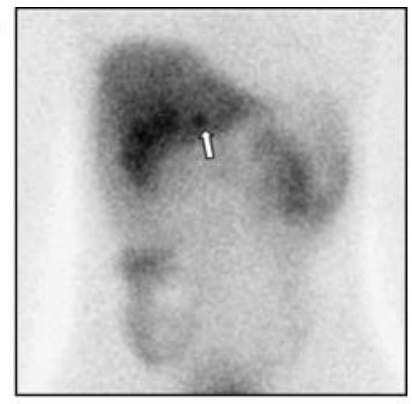

C 1

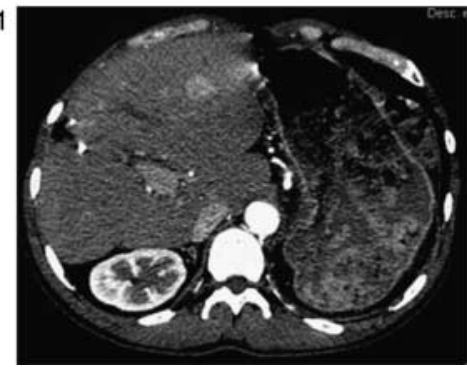

B

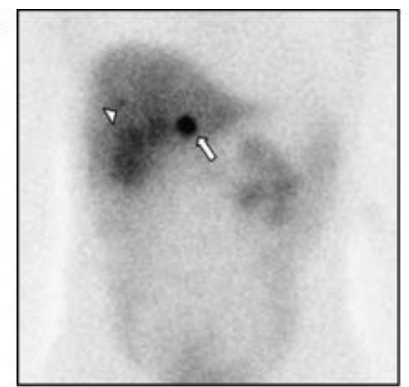

$\mathrm{C} 2$

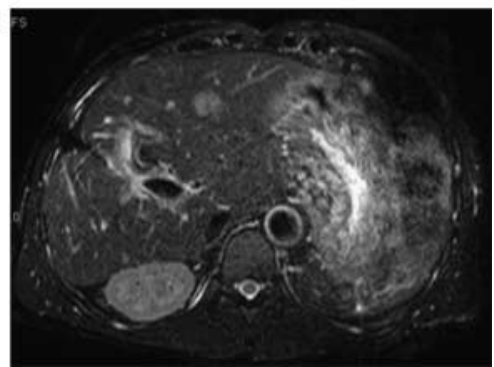

Figure 3 A 52-year-old patient operated on for a pancreatic primary with synchronous liver metastases. SRS was performed during systematic follow-up (anterior abdominal views acquired $24 \mathrm{~h}$ after injection of ${ }^{111} \mathrm{In}$-DTPA-octreotide). (A) SRS showed one focus of uptake in the liver (white arrow) 9 years after initial surgery; abdominal CT and liver MRI were normal and no tumor recurrence was considered. (B) Seventeen months later, the focus of uptake was more intense (white arrow), an additional small focus appeared in the right liver (white arrowhead), abdominal CT was still normal; (C) Six months later, CT (C1, hepatic arterial phase after i.v. injection of contrast material) and MRI (C2, fast-spin echo fat-suppressed T2-weighted sequence) showed corresponding metastasis of $22 \mathrm{~mm}$ in the left liver.

the need for an efficient adjuvant therapy that could eradicate occult metastases and thus maximize the benefit of aggressive liver surgery. Perhaps, more targeted post-operative approaches could help to prevent or delay tumor recurrence after hepatic resection, such as somatostatin analogues (Norton 2005), peptide receptor radionuclide therapy (Krenning et al. 1999, Kwekkeboom et al. 2000), and antiangiogenic drugs.
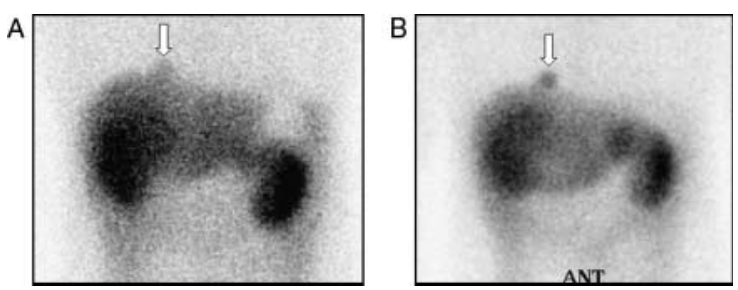

Figure 4 A 44-year-old patient operated on for a pancreatic primary with synchronous liver metastases. SRS was performed during systematic follow-up (anterior abdominal views acquired $24 \mathrm{~h}$ after injection of ${ }^{111}$ In-DTPA-octreotide). (A) SRS showed a focus of uptake above the liver (white arrow) 19 months after liver surgery; thoraco-abdominal CT was normal. (B) Six months later, the focus of uptake was more intense (white arrow), and thoracic-abdominal CT showed a corresponding supra-diaphragmatic nodular lesion $(15 \mathrm{~mm})$, that was then resected.
The second part of our study evaluated the usefulness of imaging studies to detect recurrences during follow-up. SRS has shown to be very sensitive and specific for the detection and staging of endocrine tumors and their hepatic and extra-hepatic metastases, both for functioning and non-functioning endocrine tumors (Scherubl et al. 1993, Gibril et al. 1996, Lebtahi et al. 1997, Kwekkeboom et al. 2000, Sundin et al. 2007). Here, we focused on the respective values of SRS and MI studies to detect endocrine tumor recurrences during follow-up after liver surgery. SRS had significantly higher accuracy than MI, and particularly higher sensitivity and NPV. When differentiating results for various tumor sites, SRS also showed a significantly higher sensitivity for thoracic lymph nodes and bone lesions. Notably, SRS permitted to detect recurrences earlier than MI studies in 11 out of 32 patients (34\%): SRS showed the disease as early as 31 months (median: 15.5 months, range: 5-31) before MI, both for hepatic and extrahepatic lesions. Recurrent tumors earlier detected by SRS were always apparent later on MI explorations, suggesting the precocity of functional versus morphological recurrence. MI defines disease states on the basis of macroscopic anatomical changes; functional imaging provides information on the biological 
processes (i.e. expression of somatostatin receptors by endocrine tumor cells) that may precede anatomical changes. Many of the lesions earlier detected by SRS were small (as small as $6 \mathrm{~mm}$ ). The main explanation is that, although SRS has a limited spatial resolution $(10 \mathrm{~mm})$, smaller lesions can be detected due to their high density of somatostatin receptors (Plöckinger \& Wiedenmann 2005). This is particularly relevant for lymph nodes, because morphological criteria, mainly based on size, cannot distinguish with certainty all involved lymph nodes. Therapeutic implications of such early diagnosis of recurrence remain to be determined. In our series, early abnormal scintigraphic findings did not lead to immediate therapeutic decisions, but prompted the referring clinicians to obtain closer follow-up MI studies. Therapeutic management was then altered in all concerned patients, when subsequent MI depicted abnormalities corresponding to previously seen scintigraphic abnormalities. Early detection of abnormal nonphysiological foci of uptake on SRS studies without corresponding morphological lesion should lead to schedule closer MI evaluations during follow-up.

Our study has obvious limitations related to its retrospective design. First, imaging techniques continuously evolved during the study period and liver MRI was performed only in recent years. In the late 1990s, SRS was reported to be the single most sensitive imaging technique when compared with CT,
MRI, US, and selective angiography to detect liver metastases from gastrinoma: SRS and MRI had a sensitivity of 92 and $71 \%$ respectively (Gibril et al. 1996). In a recent study comparing SRS, MRI, and CT to detect endocrine liver metastases, MRI has been found to be the superior method; false-negative SRS results were mostly observed in cases of small metastases (Dromain et al. 2005). The combined use of these two imaging techniques might achieve the most accurate disease evaluation for the liver. All imaging studies, both radiological and scintigraphic, had been performed according to the state of the art criteria of the moment. Liver endocrine metastases are hypervascular lesions supplied by the hepatic artery (Paulson et al. 1998, Foley et al. 2000). Their detection with MI requires thus acquisition during the hepatic arterial phase (starting $30 \mathrm{~s}$ after the beginning of contrast injection) when hypervascular tumors are hyperattenuating because they enhance more than the surrounding parenchyma (Foley et al. 2000, Kopp et al. 2002). Unenhanced contrast or portal venous phase (starting $60 \mathrm{~s}$ after the beginning of contrast injection) imaging alone can miss hypervascular lesions because they may appear iso or hypoattenuating (Patten et al. 1993, Baron 1994). During the arterial phase, 30\% more endocrine liver metastases are found including $6 \%$ of metastatic patients exclusively evidenced during this phase (Paulson et al. 1998). In our institution, when patients had suspected or histologically proven
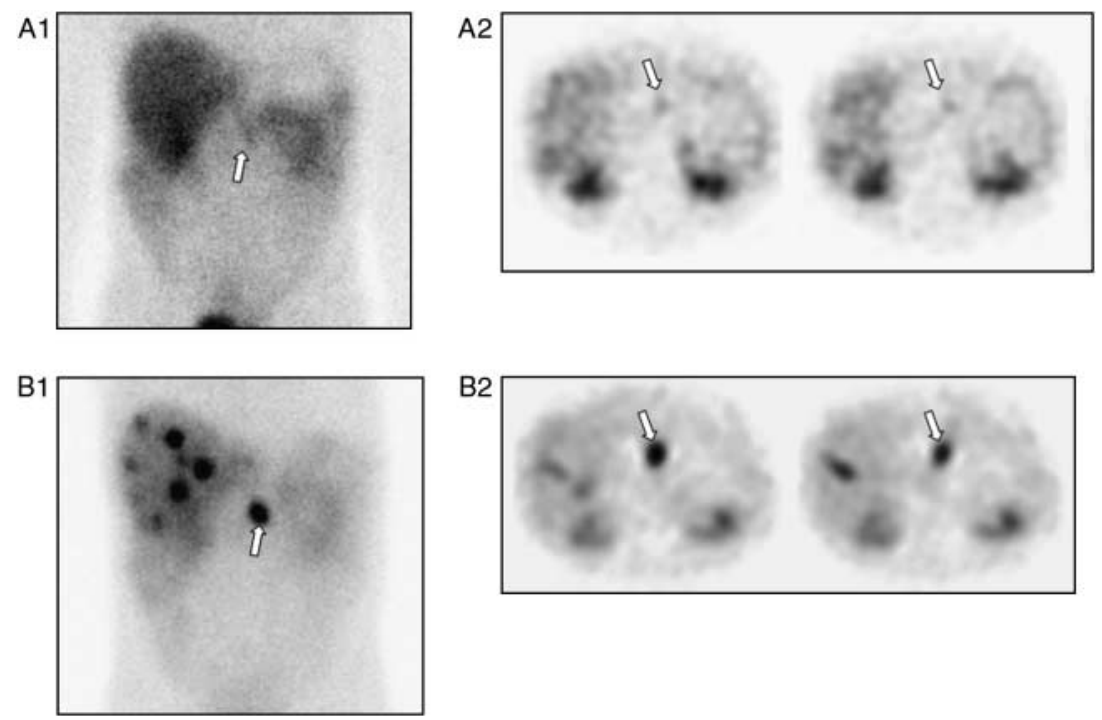

Figure 5 A 58-year-old patient operated on for a pancreatic primary with synchronous liver metastases. SRS was performed during follow-up (anterior abdominal views and abdominal axial single-photon emission-computed tomography acquired $24 \mathrm{~h}$ after injection of ${ }^{111}$ In-DTPA-octreotide). (A1 and A2) SRS showed one slight focus of uptake in the pancreatic area (white arrow) 23 months after liver surgery; abdominal CT was normal and showed one $15 \mathrm{~mm}$ lesion in the remnant pancreas 7 months later. The patient was followed with no therapeutic intervention. (B1 and B2) Eight months later, the pancreatic focus of uptake (white arrow) was evident and multiple hepatic metastatic foci appeared. 
endocrine tumor, CT imaging protocols always included a hepatic arterial phase acquisition to ensure maximal detection of metastases in the liver. When slower CT scanning technology was used (before 1996), liver imaging encompassed both arterial and venous phases of contrast enhancement, consequently decreasing sensitivity to detect hepatic metastases compared with faster techniques using multislice helical CT (after 1996). But this accounted for a minority of the examinations ( 3 out of 136) analyzed in this study. Second, only the original interpretation of SRS and MI studies was used in the analysis, and retrospective reinterpretation of the images was not included. Imaging studies were interpreted by either experienced radiologists or nuclear medicine physicians of the same institution. This study is thus the reflection of daily clinical practice in our institution serving as tertiary center for the management of patients with endocrine tumors.

In conclusion, despite exhaustive liver surgery for endocrine tumor metastases, most patients will develop hepatic and/or extra-hepatic recurrences, rather early after liver surgery (median recurrence time of 19 months), suggesting that microscopic disease remains and should be the target of an efficient adjuvant therapy to enhance the benefit of surgery and prolong recurrence-free survival. SRS appears to be highly sensitive for the detection of recurrences during post-operative follow-up and seems to permit early diagnosis of recurrences in one third of patients.

\section{Declaration of interest}

We declare that we have no conflict of interest.

\section{Funding}

This work did not receive any specific grant from any funding agency in the public, commercial, or not-for-profit sector.

\section{Acknowledgements}

We thank C Latarche (Department of Epidemiology, University Hospital of Nancy, France) for statistical analysis.

\section{References}

Ahlman H, Wangberg B, Jansson S, Friman S, Olausson M, Tylen U \& Nilsson O 2000 Interventional treatment of gastrointestinal neuroendocrine tumours. Digestion 62 $59-68$.

Baron RL 1994 Understanding and optimizing use of contrast material for CT of the liver. American Journal of Roentgenology 163 323-331.
Chamberlain RS, Canes D, Brown KT, Saltz L, Jarnagin W, Fong Y \& Blumgart LH 2000 Hepatic neuroendocrine metastases: does intervention alter outcomes? Journal of the American College of Surgeons $190432-445$.

Chen H, Hardacre JM, Uzar A, Cameron JL \& Choti MA 1998 Isolated liver metastases from neuroendocrine tumors: does resection prolong survival? Journal of the American College of Surgeons 187 88-92.

Dromain C, De Baere T, Lumbroso J, Caillet H, Laplanche A, Boige V, Ducreux M, Duvillard P, Elias D, Schlumberger M et al. 2005 Detection of liver metastases from endocrine tumors: a prospective comparison of somatostatin receptor scintigraphy, computed tomography, and magnetic resonance imaging. Journal of Clinical Oncology 23 70-78.

Elias D, Lasser P, Ducreux M, Duvillard P, Ouellet JF, Dromain C, Schlumberger M, Pocard M, Boige V, Miquel C et al. 2003 Liver resection (and associated extrahepatic resections) for metastatic well-differentiated endocrine tumors: a 15-year single center prospective study. Surgery 133 375-382.

Foley WD, Mallisee TA, Hohenwalter MD, Wilson CR, Quiroz FA \& Taylor AJ 2000 Multiphase hepatic CT with a multirow detector CT scanner. American Journal of Roentgenology 175 679-685.

Frilling A, Rogiers X, Malago M, Liedke OM, Kaun M \& Broelsch CE 1998 Treatment of liver metastases in patients with neuroendocrine tumors. Langenbeck's Archives of Surgery 383 62-70.

Gibril F, Reynolds JC, Doppman JL, Chen CC, Venzon DJ, Termanini B, Weber HC, Stewart CA \& Jensen RT 1996 Somatostatin receptor scintigraphy: its sensitivity compared with that of other imaging methods in detecting primary and metastatic gastrinomas. Annals of Internal Medicine 125 26-34.

Janson ET, Holmberg L, Stridsberg M, Eriksson B, Theodorsson E, Wilander E \& Oberg K 1997 Carcinoid tumors: analysis of prognostic factors and survival in 301 patients from a referral center. Annals of Oncology 8 685-690.

John M, Meyerhof W, Richter D, Waser B, Schaer JC, Scherübl H, Boese-Landgraf J, Neuhaus P, Ziske C, Mölling K et al. 1996 Positive somatostatin receptor scintigraphy correlates with the presence of somatostatin receptor subtype 2. Gut 38 33-39.

Kianmanesh R, O'Toole D, Sauvanet A, Ruszniewski P \& Belghiti J 2005 Surgical treatment of gastro-enteropancreatic endocrine tumors. Part 2. Treatment of hepatic metastases. Journal de Chirurgie 142 208-219.

Kianmanesh R, Sauvanet A, Hentic O, Couvelard A, Levy P, Vilgrain V, Ruszniewski P \& Belghiti J 2008 Two-step surgery for synchronous bilobar liver metastases from digestive endocrine tumors: a safe approach for radical resection. Annals of Surgery 247 659-665.

Klöppel G, Perren A \& Heitz PU 2004 The gastroenteropancreatic neuroendocrine cell system and its tumor: the WHO classification. Annals of the New York Academy of Sciences 1014 13-27. 
Kopp AF, Heuschmid M \& Claussen CD 2002 Multidetector helical CT of the liver for tumor detection and characterization. European Radiology 12 745-752.

Krenning EP, De Jong M, Kooij PPM, Breeman WA, Bakker WH, de Herder WW, van Eijck CH, Kwekkeboom DJ, Jamar F, Pauwels S et al. 1999 Radiolabelled somatostatin analogue(s) for peptide receptor scintigraphy and radionuclide therapy. Annals of Oncology 10 23-29.

Kwekkeboom DJ, Krenning EP \& De Jong M 2000 Peptide receptor imaging and therapy. Journal of Nuclear Medicine 41 1704-1713.

Lebtahi R, Cadiot G, Sarda L, Daou D, Faraggi M, Petegnief Y, Mignon M \& le Guludec D 1997 Clinical impact of somatostatin receptor scintigraphy in the management of patients with neuroendocrine gastroenteropancreatic tumors. Journal of Nuclear Medicine 38 853-858.

Lebtahi R, Le Cloirec J, Houzard C, Daou D, Sobhani I, Sassolas G, Mignon M, Bourguet P \& Le Guludec D 2002 Detection of neuroendocrine tumors: ${ }^{99 \mathrm{~m}}$ Tc-P829 scintigraphy compared with ${ }^{111}$ In-Pentetreotide scintigraphy. Journal of Nuclear Medicine 43 889-895.

Lewin M, Handra-Luca A, Arrivé L, Wendum D, Paradis V, Bridel E, Fléjou JF, Belghiti J, Tubiana JM \& Vilgrain V 2006 Liver adenomatosis: classification of MR imaging features and comparison with pathologic findings. Radiology 241 433-440.

Madeira I, Terris B, Voss M, Denys A, Sauvanet A, Flejou JF, Vilgrain V, Belghiti J, Bernades P \& Ruszniewski P 1998 Prognostic factors in patients with endocrine tumours of the duodenopancreatic area. Gut 43 422-427.

Maire F, Hammel P, Kianmanesh R, Hentic O, Couvelard A, Rebours V, Zappa M, Raymond E, Sauvanet A, Louvet C et al. 2009 Is adjuvant therapy with streptozotocin and 5-fluorouracil useful after resection of liver metastases from digestive endocrine tumors? Surgery 145 69-75.

Mignon M 2000 Natural history of neuroendocrine enteropancreatic tumors. Digestion 6 51-58.

Moertel CG 1987 Karnofsky memorial lecture. An odyssey in the land of small tumors. Journal of Clinical Oncology 5 1502-1522.

Musunuru S, Chen H, Rajpal S, Stephani N, McDermott JC, Holen K, Rikkers LF \& Weber SM 2006 Metastatic neuroendocrine hepatic tumors: resection improves survival. Archives of Surgery 141 1000-1004.

Nave H, Mössinger E, Feist H, Lang H \& Raab H 2001 Surgery as primary treatment in patients with liver metastases from carcinoid tumors: a retrospective, unicentric study over 13 years. Surgery 129 170-175.

Norton JA 2005 Endocrine tumours of the gastrointestinal tract. Surgical treatment of neuroendocrine metastases. Best Practice \& Research. Clinical Gastroenterology 19 577-583.
Norton JA, Warren RS, Kelly MG, Zuraek MB \& Jensen RT 2003 Aggressive surgery for metastatic liver neuroendocrine tumors. Surgery 134 1057-1063.

Patten RM, Byun JY \& Freeny PC 1993 CT of hypervascular hepatic tumors: are unenhanced scans necessary for diagnosis? American Journal of Roentgenology 161 979-984.

Paulson EK, McDermott VG, Keogan MT, DeLong DM, Frederick MG \& Nelson RC 1998 Carcinoid metastases to the liver: role of triple-phase helical CT. Radiology 206 143-150.

Plöckinger U \& Wiedenmann B 2005 Endocrine tumours of the gastrointestinal tract. Management of metastatic endocrine tumours. Best Practice \& Research. Clinical Gastroenterology 19 553-576.

Que FG, Nagorney DM, Batts KP, Linz LJ \& Kvols LK 1995 Hepatic resection for metastatic neuroendocrine carcinomas. American Journal of Surgery 169 36-42.

Reubi JC, Hacki WH \& Lamberts SW 1987 Hormoneproducing gastrointestinal tumors contain a high density of somatostatin receptors. Journal of Clinical Endocrinology and Metabolism 65 1127-1134.

Reubi JC, Kvols L, Krenning EP \& Lamberts SW 1990 Distribution of somatostatin receptors in normal and tumor tissue. Metabolism 39 78-81.

Reubi JC, Schar JC, Waser B, Wenger S, Heppeler A, Schmitt JS \& Mäcke HR 2000 Affinity profiles for human somatostatin receptor subtypes SST1-SST5 of somatostatin radiotracers selected for scintigraphic and radiotherapeutic use. European Journal of Nuclear Medicine 27 273-282.

Sarmiento JM, Que FG, Grant CS, Thompson GB, Farnell MB \& Nagorney DM 2002 Concurrent resections of pancreatic islet cell cancers with synchronous hepatic metastases: outcomes of an aggressive approach. Surgery 132 976-982.

Sarmiento JM, Heywood G, Rubin J, Ilstrup DM, Nagorney DM \& Que FG 2003 Surgical treatment of neuroendocrine metastases to the liver: a plea for resection to increase survival. Journal of the American College of Surgeons 197 29-37.

Scherubl H, Bader M, Fett U, Hamm B, Schmidt-Gayk H, Koppenhagen K, Dop FJ, Riecken EO \& Wiedenmann B 1993 Somatostatin-receptor imaging of neuroendocrine gastroenteropancreatic tumors. Gastroenterology 105 1705-1709.

Solcia E, Klöppel G \& Sobin LH 2000 Histological typing of endocrine tumours. In World Health Organization International Histological Classification of Tumours, edn 2, pp 61-68. Berlin: Springer.

Steinmüller T, Kianmanesh R, Falconi M, Scarpa A, Taal B, Kwekkeboom DJ, Lopes JM, Perren A, Nikou G, Yao J et al. 2008 Consensus guidelines for the management of patients with liver metastases from digestive (neuro)endocrine tumors: foregut, midgut, hindgut, and unknown primary. Neuroendocrinology 87 47-62. 
Sundin A, Garske U \& Orlefors H 2007 Nuclear imaging of neuroendocrine tumours. Best Practice and Research. Clinical Endocrinology and Metabolism 21 69-85.

Vilgrain V 2003 Multidetector CT and MRI of malignant liver tumors. Journal de Radiologie 84 459-470.

Weber HC, Venzon DJ, Lin JT, Fishbein VA, Orbuch M, Strader DB, Gibril F, Metz DC, Fraker DL, Norton JA et al. 1995 Determinants of metastatic rate and survival in patients with Zollinger-Ellison syndrome: a prospective long-term study. Gastroenterology 108 1637-1649.

Yu F, Venzon DJ, Serrano J, Goebel SU, Doppman JL, Gibril F \& Jensen RT 1999 Prospective study of the clinical course, prognostic factors, causes of death, and survival in patients with long-standing Zollinger-Ellison syndrome. Journal of Clinical Oncology 17 615-630. 